\title{
Determination of Phenoxyacetic Acids and Chlorophenols in Aqueous Samples by Dynamic Liquid-Liquid-Liquid Microextraction with Ion-Pair Liquid Chromatography
}

\author{
Ming-Kung YeH, ${ }^{*}$ Shu-Ling Lin, ${ }^{* *}$ Mei-I Leong, ${ }^{*}$ Shang-Da Huang, ${ }^{* \dagger}$ and Ming-Ren FuH**† \\ *Department of Chemistry, National Tsing Hua University, Hsinchu 30013, Taiwan \\ **Department of Chemistry, Soochow University, Taipei, Taiwan
}

\begin{abstract}
Dynamic liquid-liquid-liquid microextraction coupled with ion-pair liquid chromatography (IP-LC) and photodiode array detection was developed and used for the extraction and analysis of chlorinated phenoxyacetic acids (CPAs) and chlorophenols (CPs) from water samples. An organic extraction solvent mixture was chosen to simultaneously and effectively extract both CPAs and CPs from aqueous samples. The method detection limit (MDL) ranged from 0.06 to $0.45 \mu \mathrm{g} \mathrm{L}^{-1}$ with good reproducibility. The relative standard deviations were in the range of $2.6-6.5 \%$ at lower spiked concentrations and 3.0-4.6\% at higher concentrations. Good linearity of analytes was achieved in the range of $0.5-500 \mu \mathrm{g} \mathrm{L}^{-1}$. The acceptable relative recoveries $(82.9-112.4 \%)$ for environmental waters revealed the presence of negligible matrix effects in the case of real samples. The applicability of this newly developed method was illustrated by determinations of CPAs and CPs in environmental water samples.
\end{abstract}

(Received July 19, 2010; Accepted October 18, 2010; Published January 10, 2011)

Chlorinated phenoxyacetic acids (CPAs), as herbicides and plant growth regulators, are extensively used for the selective control of a wide range of broadleaf weeds in lawns, crops, and cereals. ${ }^{1}$ CPAs are known to have adverse effects on human health. Farmers in mid-western United States who applied large quantities of 2,4-dichlorophenoxyacetic acid (2,4-D) were found to have increased incidence of non-Hodgkin's lymphoma. ${ }^{2}$ Chlorophenols (CPs) are commonly used as insecticides, herbicides, and wood preservatives. Some CPs, such as 2,4-dichlorophenol (2,4-DCP) and pentachlorophenol (PCP), are suspected endocrine disruptors and carcinogens. ${ }^{2,3}$ According to US EPA regulations, the maximum contaminant levels (MCLs) of 2,4-D and PCP in drinking water are 70 and $1 \mu \mathrm{g} \mathrm{L}^{-1}$, respectively. ${ }^{4}$

CPAs and CPs are closely related to dioxins. For example, industrial synthesis of 2,4,5-trichlorophenoxyacetic acid (2,4,5-T) from 2,4,5-trichlorophenol (2,4,5-TCP), under alkaline conditions, leads to a side reaction that produces dioxins. Octachlorodibenzo- $p$-dioxin (OCDD), a chlorinated dioxin, may also be generated when PCP-treated woods were burned. ${ }^{2}$ Commercial supplies of CPAs and CPs are also known to be contaminated with various dioxins. In addition, CPAs present in soil are generally degraded to phenolic metabolites. ${ }^{5,6}$ Therefore, the simultaneous determination of CPAs and CPs is necessary due to their close relationship and potential contribution to environmental contamination together with dioxins.

CPAs and CPs are benzene derivatives that exhibit an auxochromic effect, which shifts their characteristic chromophore peaks to longer wavelengths and increases their intensities. ${ }^{7}$ Pronounced auxochromic effects are found in

† To whom correspondence should be addressed.

E-mail: sdhuang@mx.nthu.edu.tw (S.-D. H.); sjbfuh@yahoo.com or msfuh@scu.edu.tw (M.-R. F.) anionic CPAs and CPs due to the appearance of an extra pair of unshared electrons on oxygen, which contributes to the conjugation with either the $\pi$ electrons of the ring on CPs or the carbonyl group on CPAs. In order to lower the detection limit of CPs, one can choose a wavelength within their anionic $\mathrm{E}_{2}$ bands $(238-256 \mathrm{~nm})$ for individual CPs to determine their amounts in aqueous samples. In the case of anionic CPAs, a wavelength within their weaker B bands $(273-290 \mathrm{~nm})$ is used for quantification due to a higher signal-to-noise ratio $(S / N)$ than that of the $\mathrm{E}_{2}$ bands. Ion-pair liquid chromatography (IP-LC) with photodiode array detection can be utilized to separate anionic CPAs/CPs and maintain their ionic states to enhance the sensitivity for quantifying the target analytes.

Various extraction and detection methods have been reported for the determination of CPAs and CPs. Liquid-liquid extraction ${ }^{8}$ and Soxhlet extraction ${ }^{9}$ were frequently used to extract CPAs/CPs and these two techniques were coupled with gas chromatography (GC) for the determination. However, these extraction techniques are usually time-consuming and require large quantities of organic solvent. Moreover, derivatization is necessary for CPAs/CPs to be determined by GC. In addition, solid-phase extraction (SPE) has been used to isolate and preconcentrate these analytes. ${ }^{5,6}$ Although this approach resulted in high extraction yields, considerable amounts of time and solvent were still required for the extraction process. Solid phase microextraction (SPME), a solvent-free extraction technique, coupled with HPLC overcomes the drawbacks mentioned above. ${ }^{10,11}$ However, due to the limited lifetime and availability of the commercial polymer-coated fibers, the determination of analytes with big difference in polarity is usually difficult using SPME for sample preparation. ${ }^{12}$ Liquid-liquid-liquid microextraction (LLLME) ${ }^{13}$ coupled with HPLC for the determination of CPAs or CPs in water ${ }^{12,14-18}$ has been reported as an environment-friendly technique and requires 
a relatively simple instrumental setup for the analysis. LLLME can be easily operated and is suitable for ionizable compounds. In addition, the aqueous acceptor phase can be directly injected into a HPLC system without derivatization.

In the present study, we exploited LLLME with automated movement of the acceptor and donor phases (LLLME/AMADP or dynamic LLLME, achieved by a syringe pump) to increase the mass transfer of the analytes into the acceptor phase; this strategy therefore, enhances the extraction efficiency. ${ }^{14,17,19}$ In dynamic LLLME, CPAs and CPs were extracted from an acidified aqueous donor phase into the organic solvent in the pores and the lumen of a hollow fiber. The analytes were further deprotonated and extracted into a basic acceptor phase inside the lumen of the hollow fiber and the microsyringe barrel. Factors including the acceptor phase volume, extraction time, agitation of the donor solution, composition of the donor and acceptor phases, and salt addition were optimized to achieve high extraction efficiency for target analytes. The applicability of dynamic LLLME coupled to IP-LC/PDA was demonstrated by determining CPAs and CPs in reservoir, tap, and river water samples.

\section{Experimental}

\section{Reagents and chemicals}

$o$-Chlorophenoxyacetic acid (o-CPA), $p$-chlorophenoxyacetic acid ( $p$-CPA), 2,4,5-T, 2,4,6-trichlorophenol (2,4,6-TCP), and PCP were purchased from Chem Service (PA). 2,4-D, 2-chlorophenol (2-CP), and 2,4-DCP were obtained from Sigma-Aldrich Chemie GmbH (Steinheim, Germany). Tetraethylammonium hydroxide (TEA-OH) solution was purchased from Fluka Chemicals GmbH (Buchs, Switzerland). Methanol and acetonitrile (ACN) used in this study were HPLC grade and were purchased from J. T. Baker (Philipsburg, NJ). 1-Octanol, 1-nonanol, 4-nitro-m-xylene, and 4-nitro-o-xylene were obtained from Sigma-Aldrich Chemie $\mathrm{GmbH}$. 1,2,4-Trichlorobenzene (1,2,4-TCB) was from Janssen Chimica (Geel, Belgium), and diisobutyl ketone was purchased from TCI (Tokyo Kasei Kogyo Co. Ltd., Tokyo, Japan). Sodium hydrogen carbonate (Merck, Darmstadt, F. R. Germany) was used for adjusting the $\mathrm{pH}$ of the mobile phase. The stock solutions of $\mathrm{CPA}$ and $\mathrm{CP}$ were prepared at $1 \mu \mathrm{g} \mathrm{L}^{-1}$ in methanol, and their working solutions $\left(200 \mu \mathrm{g} \mathrm{L}^{-1}\right)$ were diluted daily from the stock solution with water. The deionized water used in all the experiments was obtained from a Milli-Q water purification system (Millipore, Bedford, MA). Reagents and solvents used in this study were all analytical grade or LC grade, unless otherwise mentioned.

A Q3/2 Accurel polypropylene hollow fiber $(600 \mu \mathrm{m}$ i.d., $200 \mu \mathrm{m}$ wall thickness, $0.2 \mu \mathrm{m}$ pore size) was purchased from Membrana $\mathrm{GmbH}$ (Wuppertal, Germany). The hollow fiber was cut into $4.0-\mathrm{cm}$ segments, cleaned ultrasonically with acetone, and oven-dried prior to use. Sodium thiosulfate $(80 \mathrm{mg})$ was added to $1 \mathrm{~L}$ of tap water collected in our laboratory to neutralize any residual chlorine or hypochlorite present in the water sample. The river water (from the Tao-Cheng River in the Hsinchu area), tap water, and reservoir water (from a local reservoir) samples were filtered through an Advantec Number 2 filter paper prior to dynamic LLLME.

\section{IP-LC method}

A HPLC system (Waters, Milford, MA) consisting of a Waters 2695 Separations Module, a Waters 2996 photodiode array detector, and a XBridge C18 column $(4.6 \times 250 \mathrm{~mm}, 5 \mu \mathrm{m})$ was employed for determining CPAs and CPs. Waters
Empower software was used for system control and data analysis. A Model 200 series programmable syringe pump (KD Scientific Inc., MA) and a $25-\mu \mathrm{L}$ LC syringe (Hamilton, Reno, $\mathrm{NV}$ ) were utilized for the study. Chromatographic separation was performed using $\mathrm{ACN}$ and $4 \mathrm{mM}$ TEA-OH $\mathrm{OH}_{(\mathrm{aq})}(\mathrm{pH} 10)$ as mobile phases for gradient elution. The flow rate was set at

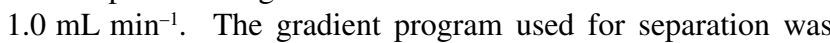
summarized as follows: an initial isocratic elution at $8 \% \mathrm{ACN}$ for $10 \mathrm{~min}$, linearly increased $\mathrm{ACN}$ to $35 \%$ in the next $25 \mathrm{~min}$, and further increased to $55 \% \mathrm{ACN}$ in $5 \mathrm{~min}$. Detection was carried out at the characteristic wavelength of each analyte, as shown in Table 1.

\section{Dynamic LLLME}

Similar to the experimental setup described by Lee's group, ${ }^{17}$ a 14-ml volume of an acidified aqueous solution (donor phase; to a final concentration of $0.1 \mathrm{M} \mathrm{HCl}$ ) containing $7.5 \% \mathrm{NaCl}$ (w/v) and $200 \mu \mathrm{g} \mathrm{L}^{-1}$ of each analyte was placed in a $16-\mathrm{mL}$ brown sample vial together with a stir bar. Fifteen microliters of acceptor solution $(0.2 \mathrm{M} \mathrm{NaOH})$ were withdrawn into a $25-\mu \mathrm{L}$ microsyringe, which could accommodate up to $30 \mu \mathrm{L}$ solution including the space beyond the mark, and sequentially followed by $3 \mu \mathrm{L}$ of mixed organic solvent (1,2,4-trichlorobenzene:1-octanol/60:40), $2.5 \mu \mathrm{L}$ of deionized water, and $\sim 7.5 \mu \mathrm{L}$ of air. The needle tip of the syringe was then inserted into the hollow fiber and immersed the fiber into the selected organic solvent to impregnate the pores of the hollow fiber. After impregnation, the air in the syringe was injected into the hollow fiber to remove excess organic solvent present in the fiber lumen. Water was injected to further flush the interior of the fiber and prevent the organic phase from contacting with air in the subsequent steps. The fiber was then immersed in deionized water, and all of the organic solvent as well as $7.5 \mu \mathrm{L}$ of the acceptor phase was injected into the fiber (the lumen volume of the $4-\mathrm{cm}$ fiber was $\sim 10.5 \mu \mathrm{L}$ ) leaving $7.5 \mu \mathrm{L}$ of the acceptor solution in the syringe. This step was performed to equalize the volume of the organic solvent in each extraction step.

Upon immersion, the entire assembly was mounted onto a syringe pump that was programmed to continuously move the plunger of the syringe between 7.5 and $15 \mu \mathrm{L}$ at a rate of $40 \mu \mathrm{L} \mathrm{min}{ }^{-1} .^{20}$ After extraction for $60 \mathrm{~min}$ at the stirring rate of $1100 \mathrm{rpm}$, the syringe pump and stirrer were switched off, and all remaining acceptor phase was retracted and injected into the HPLC system for analysis.

\section{Results and Discussion}

Investigation of experimental parameters for dynamic LLLME Selection of the organic solvent. An ideal extraction solvent for LLLME will have the following characteristics: ${ }^{13}$ (1) be easily immobilized in the pores of the polypropylene hollow fiber, (2) have a low vapor pressure, (3) be immiscible with water (donor and acceptor phases), and (4) have high solubility for the target analytes. Based on these criteria, 1-octanol, 1-nonanol, 4-nitro- $m$-xylene, 4-nitro- $o$-xylene, and 1,2,4-TCB were chosen to be candidates of organic extraction solvents for the study. The preliminary results (data not shown) indicated that 1-octanol met most of the requirements and could be used to extract CPAs. A previous publication ${ }^{21}$ also demonstrated that a polar extraction solvent was preferred for efficient extraction of polar analytes from aqueous solutions. 1,2,4-TCB was suitable for CPs and 2,4,5-T due to its low polarity and structural similarity. 4-Nitro- $m$-xylene, a solvent with a high dielectric constant, has both polar and nonpolar groups and gave more acceptable 


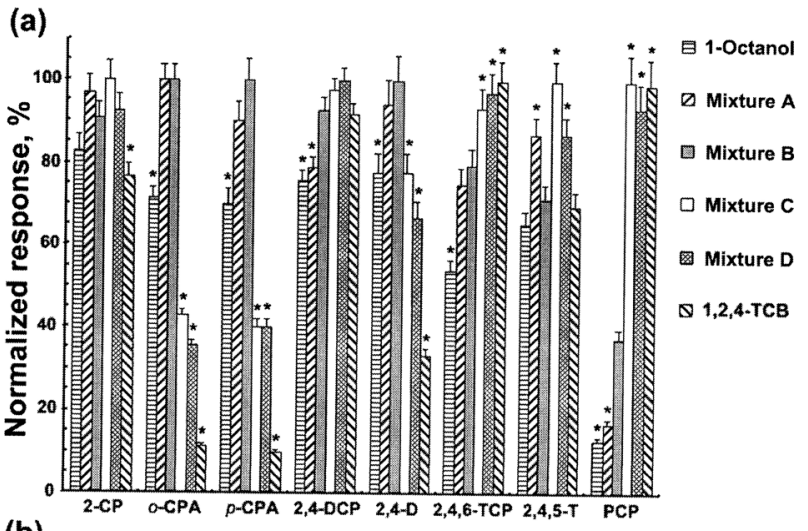

(b)

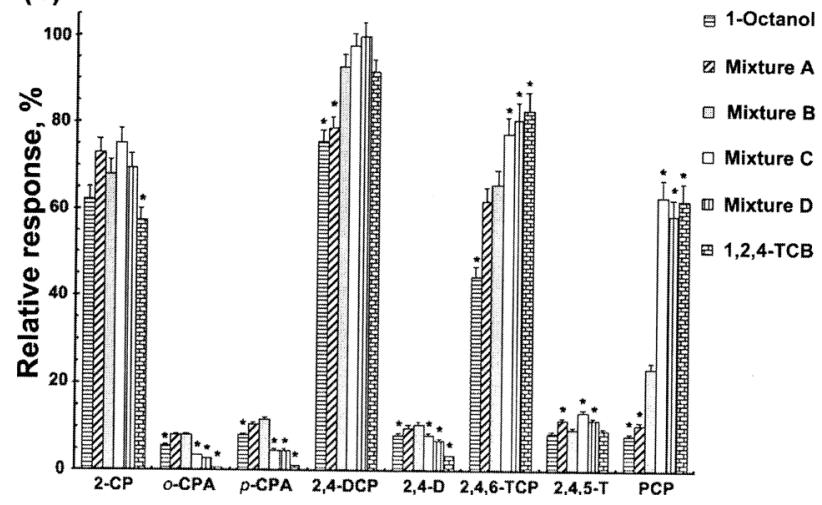

Fig. 1 Effect of organic solvents on extraction efficiency. (a) Normalized response to the highest signal of individual analyte using different extraction solvents $(n=3)$. (b) Relative response to the highest signal among all analytes using different extraction solvents $(n=3)$. Organic solvents: 1-octanol, 1,2,4-TCB and the following mixed solvent combinations. (A) 4-Nitro- $m$-xylene:1-octanol, 60\%:40\% (v/v); (B) 1,2,4-TCB:1-octanol, 60\%:40\% (v/v); (C) 1,2,4-TCB:diisobutyl ketone, $70 \%: 30 \% \quad(\mathrm{v} / \mathrm{v})$; (D) 4-nitro-mxylene:iisobutyl ketone, $80 \%: 20 \%(\mathrm{v} / \mathrm{v})$. Conditions: $14 \mathrm{~mL}$ of spiked sample solution $\left(200 \mu \mathrm{g} \mathrm{L}^{-1}\right.$ each) containing $0.1 \mathrm{M} \mathrm{HCl}$ and $7.5 \%$ (w/v) $\mathrm{NaCl} ; 3 \mu \mathrm{L}$ of indicated organic solvent; acceptor phase, $10 \mu \mathrm{L}$ of $0.1 \mathrm{M} \mathrm{NaOH}$; agitation rate, $500 \mathrm{rpm}$; extraction time, $40 \mathrm{~min}$.

results for both CPAs and CPs with the exception of mono-CPA. Therefore, various combinations of mixed solvent were investigated to improve the extraction efficiency of CPAs without significant decrease in that of CPs. In addition to the organic solvents mentioned above, diisobutyl ketone was combined with 4-nitro- $m$-xylene or 1,2,4-TCB to adjust the polarity of the mixed extraction solvent and try to improve the extraction efficiency of CPAs. As shown in Fig. 1a (normalized responses to the highest signal of individual analyte using different extraction solvent, $n=3$ ), mixed solvents $\mathrm{C}$, D and 1,2,4-TCB showed relatively high extraction capability for CPs. However, compared to other extraction solvents, they could not effectively extract CPAs, especially for $o$-CPA and $p$-CPA, from aqueous samples. Mixed solvent B (a mixture of 1-octanol and 1,2,4-TCB) exhibited an appropriate extraction solvent for most analytes compared to other combinations indicated in the figure (Fig. 1b, $n=3$ ). This observation was further confirmed by statistical analysis (two-tailed unpaired $t$ test with Welch's correction) using GraphPad Prism 5 for the significance. The symbol "*" appearing on the figure indicated a significant change $(P<0.05)$ of response on individual analyte in each solvent compared to that in solvent combination B. For analytes with poor sensitivity, such as CPAs except 2,4,5-T, mixtures A and $\mathrm{B}$ exhibited a significant increase in extraction efficiency compared to other organic solvents shown in the figure. However, the significant decrease in extraction efficiency of PCP observed in mixture A makes mixture B suitable for simultaneous extraction of $\mathrm{CPs}$ and CPAs from aqueous samples. Thus, a mixed solvent of 1,2,4-TCB and 1-octanol $(60 \%: 40 \%, \mathrm{v} / \mathrm{v})$ was selected as the organic extraction solvent in the subsequent experiments. Moreover, due to its vulnerability and the low cost of purchasing (less than US \$1/section), the used fiber was discarded to avoid the chance of carry-over.

Effect of the acceptor phase volume. Generally, a high donor/acceptor volume ratio is beneficial to achieve a high enrichment factor for concentrating trace analytes using LLLME. ${ }^{13}$ In addition, increasing the volume of acceptor phase will enhance the amount of analytes transferred into the acceptor phase. In this study, a fixed volume of the donor phase was applied. Therefore, only the effect of acceptor phase volume was studied to improve the extraction efficiency of dynamic LLLME. At equilibrium, higher acceptor phase volume increases the mass transfer of analytes from organic phase into the acceptor phase, which increases the extraction efficiency. Due to the limited volumes of the microsyringe and the injection loop $(20 \mu \mathrm{L})$, different volumes of acceptor phase $(n=3$, $5-15 \mu \mathrm{L}$ at a $2.5-\mu \mathrm{L}$ interval) were utilized to perform dynamic LLLME. Less than $20 \mu \mathrm{L}$ of acceptor phase was obtained after extraction in all experiments and the total volume of the obtained acceptor phase, which represented the total extracted amounts of the analytes, was injected for HPLC analysis. The experimental results (Fig. 2A) showed that the amounts of extracted analytes, which corresponded to the extraction efficiency and were related to the integrated peak areas in LC, were increased for all target analytes as the volume of acceptor phase increased from 5 to $15 \mu \mathrm{L}$. This observation was also confirmed by the statistical analysis discussed in Selection of the organic solvent. According to the analytical results, the volume of acceptor phase set at $15 \mu \mathrm{L}$ showed a significant increase in extraction efficiency for most analytes except 2-CP and PCP, which exhibited insignificant changes. If the donor phase volume was fixed, the amounts of analytes transferred into the acceptor phase would increase as the volume of acceptor phase increased for extraction. Therefore, $15 \mu \mathrm{L}$ of the acceptor phase was chosen for further investigations.

Effect of the extraction time. The influence of extraction time on extraction efficiency was also examined. The extraction was carried out for various periods of time $(n=3,30-70 \mathrm{~min}$ at a 10-min interval) prior to HPLC analysis. According to the experimental results (Fig. 2B), an extraction time of $60 \mathrm{~min}$ resulted in the largest peak areas for most analytes. However, a slight decrease in peak areas was observed for several analytes as the extraction time increased to $70 \mathrm{~min}$. Statistical analysis, as discussed in Selection of the organic solvent, was also performed to examine the experimental data. Based on these statistical results, all CPAs and 2-CP showed significant increases in extraction efficiency as the extraction time was increased from 50 to $60 \mathrm{~min}$. However, no significant change was observed as the extraction time was increased from 60 to 70 min for all CPs and CPAs, which indicated that the extraction had reached the equilibrium as the extraction time set at $60 \mathrm{~min}$. Therefore, $60 \mathrm{~min}$ was selected as the extraction time in the subsequent studies.

Effect of the agitation rate. In comparison with conventional LLLME, repeated movement of the acceptor and donor phases in dynamic LLLME substantially increases the mass transfer of analytes into the acceptor phase. ${ }^{14}$ Additional agitation of the donor phase also plays a vital role to provide a fresh donor phase to the organic phase for extraction. Therefore, magnetic 

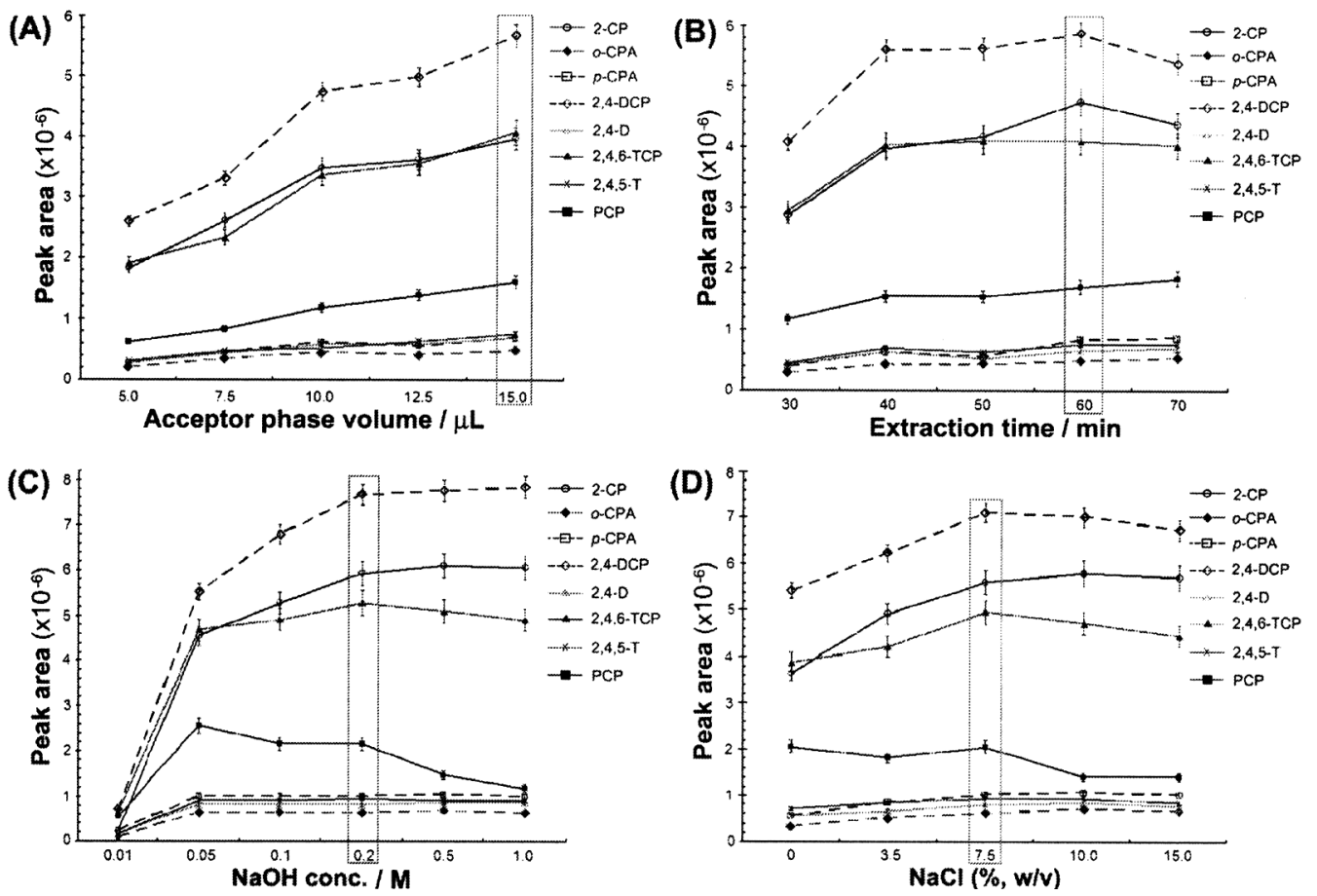

Fig. 2 Effect of selected experimental parameters on extraction efficiency. (A) Acceptor phase volume. Conditions: $14 \mathrm{~mL}$ of spiked sample solution (200 $\mu \mathrm{g} \mathrm{L}^{-1}$ each) containing $0.1 \mathrm{M} \mathrm{HCl}$ and $7.5 \%$ (w/v) NaCl; $3 \mu \mathrm{L}$ of solvent $\mathrm{B}$; acceptor phase, $0.1 \mathrm{M} \mathrm{NaOH}$ in various volumes; agitation rate, $500 \mathrm{rpm}$; extraction time, $40 \mathrm{~min}$. (B) Extraction time. Conditions: $14 \mathrm{~mL}$ of spiked sample solution $\left(200 \mu \mathrm{g} \mathrm{L}^{-1}\right.$ each) containing $0.1 \mathrm{M} \mathrm{HCl}$ and $7.5 \%$ (w/v) $\mathrm{NaCl} ; 3 \mu \mathrm{L}$ of solvent B; acceptor phase, $15 \mu \mathrm{L}$ of $0.1 \mathrm{M} \mathrm{NaOH}$; agitation rate, $500 \mathrm{rpm}$. (C) Acceptor phase basicity. Conditions: $14 \mathrm{~mL}$ of spiked sample solution $(200 \mu \mathrm{g} \mathrm{L}-1$ each) containing $0.1 \mathrm{M} \mathrm{HCl}$ and $7.5 \%$ (w/v) $\mathrm{NaCl} ; 3 \mu \mathrm{L}$ of solvent $\mathrm{B}$; acceptor phase, $15 \mu \mathrm{L}$ of $\mathrm{NaOH}$ in various concentrations; agitation rate, $1100 \mathrm{rpm}$; extraction time, $60 \mathrm{~min}$. (D) Salt addition. Conditions: $14 \mathrm{~mL}$ of spiked sample solution $\left(200 \mu \mathrm{g} \mathrm{L}^{-1}\right.$ each) containing $0.1 \mathrm{M} \mathrm{HCl}$ and various amounts of $\mathrm{NaCl} ; 3 \mu \mathrm{L}$ of solvent $\mathrm{B}$; acceptor phase, $15 \mu \mathrm{L}$ of $0.2 \mathrm{M} \mathrm{NaOH}$; agitation rate, $1100 \mathrm{rpm}$; extraction time, $60 \mathrm{~min}$. Triplicate trials were performed for each experiment.

stirring was employed to facilitate the mass transfer. An increase in peak areas ( $n=3$, data not shown) was observed when the agitation rate was increased from 300 to $1100 \mathrm{rpm}$. As the agitation rate reached $1200 \mathrm{rpm}$, the fiber started shaking vigorously to form air bubbles that attached on the fiber and decreased the extraction efficiency. Thus, an agitation rate of $1100 \mathrm{rpm}$ was chosen for further studies.

Effect of the acidity of the donor phase and the basicity of the acceptor phase. The compositions of both the donor and acceptor phases are very important parameters that affect the extraction efficiency in dynamic LLLME. For acidic analytes such as CPAs and CPs, a basic acceptor phase is required to dissolve the target analytes. In addition, the donor phase should be sufficiently acidic to retain the analytes as neutral molecules and promote the extraction into the organic phase. The effect of the basicity of acceptor phase was first examined by varying the $\mathrm{NaOH}$ concentration from 0.01 to $1 \mathrm{M}$ at a fixed composition of the donor phase $(0.1 \mathrm{M} \mathrm{HCl})$. The experimental results (Fig. 2C) showed an increase in the extraction efficiency as the concentration of $\mathrm{NaOH}$ increased from 0.01 to $0.2 \mathrm{M}$ and only small changes were obtained when $[\mathrm{NaOH}]$ is higher than $0.2 \mathrm{M}$. Hence, an acceptor phase of $0.2 \mathrm{M} \mathrm{NaOH}$ was utilized to study the influence of the acidity of donor phase using various concentrations of $\mathrm{HCl}(0.01,0.05,0.1,0.2$, and $0.3 \mathrm{M} ; n=3)$. According to the results, $0.1 \mathrm{M} \mathrm{HCl}$ gave the highest peak areas for all analytes. As the concentration of $\mathrm{HCl}$ increased from 0.05 to $0.1 \mathrm{M}$, some analytes, such as $o$-CPA, 2,4-DCP, and 2,4,6-TCP, showed a significant increase in their extraction efficiency. A significant decrease was found in all analytes as the $\mathrm{HCl}$ concentration was increased to $0.2 \mathrm{M}$. This phenomenon was due to the decreased mass transfer from the acidic donor phase into the organic phase by protonation of the hydroxyl and the carboxyl functional groups in CPs and CPAs, respectively. Therefore, $0.2 \mathrm{M} \mathrm{NaOH}$ and $0.1 \mathrm{M} \mathrm{HCl}$ were chosen as the acceptor and donor phases, respectively.

Effect of salt addition. In order to investigate the influence of ionic strength on extraction efficiency of dynamic LLLME, we performed a series of experiments by varying $\mathrm{NaCl}$ concentration $(0,3.5,7.5,10.0$, and $15 \%(\mathrm{w} / \mathrm{v}), n=3)$ in sample solutions. As shown in Fig. 2D, the analytes reached their maximum extraction efficiency at $7.5 \% \mathrm{NaCl}$ and started decreasing for most CPs but no significant changes were observed for 2-CP and CPAs when $\mathrm{NaCl}$ concentration was higher than $7.5 \%$. According to the statistical results (data not shown), most analytes (except 2,4,5-T and PCP) exhibited significant increases in extraction efficiency as the concentration of $\mathrm{NaCl}$ was increased from 3.5 to $7.5 \%$. However, no significant change was observed in all analytes except PCP when the $\mathrm{NaCl}$ concentration was higher than $7.5 \%$. This phenomenon has been reported in several publications ${ }^{12,14,16,20,22,23}$ and can be explained by the two concurrently occurring processes described by Lord and Pawliszyn. ${ }^{24}$ Initially, the salting-out effect contributed to the increase of extraction efficiency due to the increasing electrostatic interactions between water molecules and salt ions, which decreased the solubility of neutral polar analytes in the aqueous solution and promoted the extraction of analytes into organic phase, as $\mathrm{NaCl}$ concentration was increased. After reaching the maximum, a competing process 
Table 1 Analytical performance of the proposed dynamic LLLME

\begin{tabular}{lcccccc}
\hline Analyte & $\begin{array}{c}\text { Quantification } \\
\text { wavelength/nm }\end{array}$ & $\begin{array}{c}\text { Linear range/ } \\
\mu \mathrm{g} \mathrm{L}^{-1}\end{array}$ & $\begin{array}{c}\text { Correlation } \\
\text { coefficient, } r^{2}\end{array}$ & $\begin{array}{c}\text { MDL/ } \mu \mathrm{g} \mathrm{L} \mathrm{L}^{-1 \mathrm{a}, \mathrm{b}} \\
(n=7)\end{array}$ & $\begin{array}{c}\mathrm{RSD}, \%^{\mathrm{b}} \\
(n=7)\end{array}$ & $\begin{array}{c}\text { RSD, } \%^{\mathrm{c}} \\
(n=7)\end{array}$ \\
\hline 2-CP & 238 & $0.5-200$ & 0.9998 & 0.06 & 4.5 & 3.0 \\
$o$-CPA & 273 & $2-500$ & 0.9982 & 0.28 & 3.8 & 3.8 \\
$p$-CPA & 279 & $1-500$ & 0.9990 & 0.19 & 5.3 & 3.2 \\
2,4-DCP & 246 & $0.5-200$ & 0.9997 & 0.06 & 2.6 & 3.2 \\
2,4-D & 284 & $2-500$ & 0.9997 & 0.45 & 6.1 & 3.6 \\
2,4,6-TCP & 249 & $0.5-200$ & 0.9998 & 0.08 & 5.1 & 4.3 \\
2,4,5-T & 290 & $1-500$ & 0.9999 & 0.21 & 5.0 & 3.7 \\
PCP & 256 & $1-200$ & 0.9998 & 0.22 & 6.5 & 4.6 \\
\hline
\end{tabular}

a. MDL was defined as three times the standard deviation at the lowest spiked concentration. b. Spiked concentration: lowest concentration of individual linear range. c. Spiked concentration: 10-fold lowest concentration of individual linear range.

Table 2 Comparison of the present dynamic LLLME with other LPME techniques such as static LLLME, ${ }^{15}$ PDLLME ${ }^{23}$ and ultrasoundassisted headspace (UAHS) LPME ${ }^{21}$ for determining CPAs or CPs in environmental aqueous samples

\begin{tabular}{|c|c|c|c|c|c|}
\hline Comparison parameter & & Static LLLME & PDLLME & UAHS-LPME & Dynamic LLLME \\
\hline Sample volume/mL & & 50 & 5 & 10 & 14 \\
\hline Organic solvent volume $/ \mu \mathrm{L}$ & & $<10$ & 2000 & 10 & $<10$ \\
\hline Extraction time/min ${ }^{\mathrm{a}}$ & & 40 & Few seconds & 20 & 60 \\
\hline Analysis/detection & & HPLC/UV & HPLC/UV & HPLC/UV & HPLC/UV-PDA \\
\hline \multirow[t]{2}{*}{ Linear range/ng $\mathrm{mL}^{-1}$} & CPAs & $50-2000$ & $5-1000$ & N/A & $1-500$ \\
\hline & CPs & N/A & N/A & $50-2000$ & $0.5-200$ \\
\hline \multirow[t]{2}{*}{ Detection limit/ng mL $\mathrm{m}^{-1}$} & CPAs & $0.8-1.9$ & $2.3-3.3$ & N/A & $0.19-0.45$ \\
\hline & CPs & N/A & N/A & $6-23$ & $0.06-0.22$ \\
\hline \multirow[t]{2}{*}{ Precision (RSD, \%) } & CPAs & $3.8-5.9$ & $2.8-4.5$ & N/A & $3.2-6.1$ \\
\hline & CPs & N/A & N/A & $2.4-8.8$ & $2.6-6.5$ \\
\hline \multirow[t]{2}{*}{ Recovery $^{\mathrm{c}}$ (relative/absolute, $\%$ ) } & CPAs & $89-93 / \mathrm{NR}^{\mathrm{b}}$ & NR/NR & N/A & $86-105 / 23.2-31.7$ \\
\hline & CPs & N/A & N/A & $85-101 / \mathrm{NR}$ & $83-112 / 18.1-33.6$ \\
\hline
\end{tabular}

a. Time of centrifugation, evaporation, and reconstitution is not included. b. N/A, not applied; NR, not reported. c. Recovery was determined from environmental water samples.

started dominating the salting-out effect to reduce the extraction efficiency owing to the increased electrostatic interactions between polar analytes and salt ions, which decreased the ability of polar analytes to move into the organic extracting phase. Therefore, a salt concentration of $7.5 \%$ was utilized for the subsequent studies.

\section{Analytical performance}

The analytical performance of the proposed method, in terms of linearity, correlation coefficient $\left(r^{2}\right)$, precision, and method detection limit (MDL), was evaluated under the most appropriate experimental conditions described in Selection of the organic solvent (also see the Experimental section). The extracted anionic analytes were directly analyzed by IP-LC at the characteristic wavelength of each analyte. The results are summarized in Table 1. Good linearity of each analyte was achieved in their individual linear ranges with the correlation coefficients $\left(r^{2}\right)$ higher than 0.99 . The precision was evaluated on the basis of the relative standard deviations (RSD) of seven replicate experiments. The RSD values were in the range of $2.6-6.5$ and $3.0-4.6 \%$ at the lowest and highest spiked concentrations, respectively. The MDL $(3 \times \mathrm{SD}$ at the lowest spiked concentration) ranged from 0.06 to $0.45 \mu \mathrm{g} \mathrm{L}^{-1}$. The enrichment factor (EF) ranged from 145 to 279 . The EF was calculated as the ratio of the final concentration of analytes in the acceptor phase after extraction to the initial concentration of analytes in the aqueous solution. The MDLs of CPs and CPAs were lower than their MCLs set by US EPA. ${ }^{4}$ The comparison of the proposed dynamic LLLME with other LPME techniques ${ }^{16,23,25}$ for the quantitative analysis for CPAs/CPs in aqueous samples is summarized in Table 2. Some routine methodologies, such as EPA methods for determining CPs (Method 528) and CPAs (Method 515.3) in drinking water, ${ }^{26}$ reported the MDLs for CPs and CPAs at the range of $20-250 \mathrm{ng} \mathrm{mL}^{-1}$ and $0.20-0.35 \mathrm{ng} \mathrm{mL}^{-1}$, respectively. The MDLs of CPAs using the proposed dynamic LLLME method $\left(0.19-0.45 \mathrm{ng} \mathrm{mL}^{-1}\right)$ were at least one order of magnitude lower than their MCLs set by US EPA. ${ }^{4}$ These observations indicated that dynamic LLLME can be utilized to determine the amounts of trace CPAs and/or CPs in environmental water samples.

\section{Application of dynamic LLLME}

The applicability of this newly developed method was examined by determining the appearance of CPs and CPAs in reservoir, tap, and river water samples. The collected water samples were prepared to contain $7.5 \%(\mathrm{w} / \mathrm{v}) \mathrm{NaCl}$ and $0.1 \mathrm{M}$ $\mathrm{HCl}$ for the proposed dynamic LLLME. No target analytes were found in the water samples. A typical chromatogram of the extract of environmental sample is shown in Fig. 3(a). In addition, the chromatogram of the extract of reservoir water sample spiked with all the analytes $(10 \times$ lowest concentration of each analyte in their corresponding linear range) is shown in Fig. 3(b). In order to examine the matrix effect in real samples, the environmental water samples were spiked with CPAs/CPs at their lowest concentration in corresponding linear range. As seen in Table 3, the low absolute recoveries were as expected due to its partition equilibrium mechanism of LLLME/AMADP 


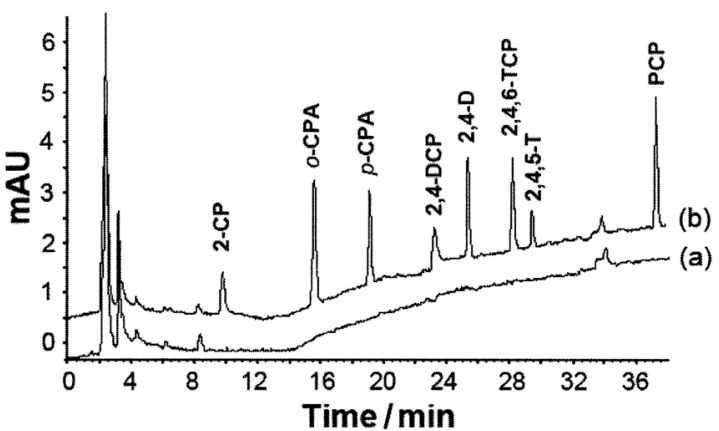

Fig. 3 Chromatograms of the extracted (a) reservoir water and (b) reservoir water spiked with all analytes. Conditions: spiked sample solution $(10 \times$ lowest concentration of each analyte in their corresponding linear range); dynamic LLLME was performed under the most appropriate conditions (see Experimental section). The detection was performed at $268 \mathrm{~nm}$.

Table 3 Relative and absolute recoveries of real water samples

\begin{tabular}{|c|c|c|c|c|c|}
\hline \multirow{2}{*}{ Analyte } & \multicolumn{3}{|c|}{ Relative recovery ${ }^{\mathrm{a}, \mathrm{b}}, \%$} & \multicolumn{2}{|c|}{$\begin{array}{c}\text { Absolute } \\
\text { recovery }, \%\end{array}$} \\
\hline & Reservoir & Tap & River & Reservoir & r Tap Rive \\
\hline $2-\mathrm{CP}$ & $105.2 \pm 1.6$ & $92.2 \pm 4.3$ & $112.4 \pm 5.3$ & 31.4 & 29.133 .6 \\
\hline$o-\mathrm{CPA}$ & $90.8 \pm 3.0$ & $93.3 \pm 5.4$ & $85.5 \pm 7.3$ & 24.6 & 26.823 .2 \\
\hline$p$-СРА & $94.5 \pm 6.5$ & $104.9 \pm 2.2$ & $94.3 \pm 4.8$ & 25.9 & 29.325 .8 \\
\hline 2,4-DCP & $84.1 \pm 1.6$ & $95.1 \pm 8.5$ & $84.8 \pm 4.1$ & 29.3 & 31.829 .5 \\
\hline $2,4-\mathrm{D}$ & $85.7 \pm 1.7$ & $88.5 \pm 3.1$ & $103.4 \pm 5.7$ & 25.5 & 27.430 .8 \\
\hline 2,4,6-ТCP & $86.7 \pm 1.9$ & $90.7 \pm 6.8$ & $82.9 \pm 4.4$ & 26.9 & 28.325 .7 \\
\hline $2,4,5-\mathrm{T}$ & $91.8 \pm 5.6$ & $92.5 \pm 7.5$ & $104.0 \pm 2.5$ & 28.0 & 28.331 .7 \\
\hline PCP & $107.3 \pm 4.7$ & $93.3 \pm 4.2$ & $106.3 \pm 2.4$ & 20.7 & 18.120 .5 \\
\hline
\end{tabular}

a. Mean $\pm \mathrm{SD}(n=3)$; $\mathrm{SD}$, standard deviation.

b. Spiked concentration: lowest concentration of individual linear range.

rather than an exhaustive extraction mechanism. Additionally, the similar recoveries for all analytes in water samples indicated that the mixed solvent described in this study can be used for simultaneous extraction of CPs and CPAs. The relative recoveries, defined as the ratio of the concentration in environmental water to that in deionized water spiked with the same amount of analytes, ${ }^{27}$ were $84.1-107.5 \%$ for reservoir water, $88.5-104.9 \%$ for tap water, and $82.9-112.4 \%$ for the river water sample. The reasonably good relative recoveries (Table 3) proved that there were negligible matrix effects using this newly developed dynamic LLLME extraction technique for determining CPs/CPAs in environmental water samples.

\section{Conclusions}

In this study, we demonstrated the ability of dynamic LLLME, which exhibited more efficient mass transfer than static LLLME, ${ }^{16}$ coupled with IP-LC/PDA for simultaneous determination of CPAs and CPs in environmental water samples. The utilization of mixed organic extraction solvent successfully allowed simultaneous extraction of CPAs and CPs from environmental waters to determine analytes with different polarity. Quantification based on the characteristic wavelengths of individual anionic analytes using IP-LC/PDA enhanced the sensitivity and obtained low MDL $\left(0.06-0.45 \mu \mathrm{g} \mathrm{L}^{-1}\right)$ for CPAs and CPs. Based on these facts, dynamic LLLME coupled with IP-LC/PDA has been illustrated as an effective and sensitive technique for the simultaneous determination of CPAs and CPs in environmental aqueous samples.

\section{Acknowledgements}

This study was supported by the National Science Council of Taiwan. The authors specially thank Tsing Hua Testing \& Analysts Co., Ltd., for kindly providing the 2,4,6-trichlorophenol and pentachlorophenol standards.

\section{References}

1. O. Chienthavorn, S. Pengpumkiat, A. Noomhormb, and R. M. Smith, J. Chromatogr., A, 2007, 1152, 268.

2. C. Baird and M. Cann, "Environmental Chemistry", 2nd ed., 1999, W. H. Freeman, New York.

3. S. G. Cooper and S. Jones, Environ. Health Perspect., 2008, 116, 1001.

4. Drinking Water Standards and Health Advisories, Office of Water, U. S. Environmental Protection Agency, Washington, D.C., 2006.

5. S. Moret, J. M. Sáncheź, V. Salvadó, and M. Hidalgo, J. Chromatogr., A, 2005, 1099, 55.

6. S. Moret, M. Hidalgo, and J. M. Sáncheź, Chromatographia, 2006, 63, 109.

7. D. A. Skoog, F. J. Holler, and T. A. Nieman, "Principles of Instrumental Analysis", 5th ed., 1998, Saunders College Publishing, USA.

8. M. J. Santos-Delgado, E. Crespo-Corral, and L. M. Polo-Díez, Talanta, 2000, 53, 367.

9. M. D. David, S. Campbell, and Q. X. Li, Anal. Chem., 2000, 72, 3665 .

10. E. Gonźalez-Toledo, M. D. Prat, and M. F. Alpendurada, J. Chromatogr., A, 2001, 923, 45.

11. A. Pẽnalver, E. Pocurull, F. Borrull, and R. M. Marcé, J. Chromatogr., A, 2002, 953, 79.

12. J. F. Peng, J. F. Liu, X. L. Hu, and G. B. Jiang, J. Chromatogr., A, 2007, 1139, 165.

13. S. Pedersen-Bjergaard and K. E. Rasmussen, Anal. Chem., 1999, 71, 2650.

14. C. C. Chen, M. B. Melwanki, and S. D. Huang, J. Chromatogr., A, 2006, 1104, 33.

15. L. Zhu, K. H. Ee, L. Zhao, and H. K. Lee, J. Chromatogr., A, 2002, 963, 335 .

16. M. B. Melwanki and S. D. Huang, Anal. Chim. Acta, 2006, $555,139$.

17. X. Jiang, S. Y. Oh, and H. K. Lee, Anal. Chem., 2005, 77, 1689.

18. J. Wu, K. H. Ee, and H. K. Lee, J. Chromatogr., A, 2005, 1082, 121.

19. L. Hou and H. K. Lee, Anal. Chem., 2003, 75, 2784.

20. C. Y. Lin and S. D. Huang, J. Chromatogr., A, 2008, 1193, 79.

21. J. Å. Jönsson, L. Mathiasson, B. Lindegård, J. Trocewicz, and A.-M. Olsson, J. Chromatogr., A, 1994, 665, 259.

22. M. Palit, D. Pardasani, A. K. Gupta, and D. K. Dubey, Anal. Chem., 2005, 77, 711.

23. H. Xu, Y. Liao, and J. Yao, J. Chromatogr., A, 2007, 1167, 1.

24. H. Lord and J. Pawliszyn, J. Chromatogr., A, 2000, 902, 17.

25. M. B. Melwanki and M.-R. Fuh, J. Chromatogr., A, 2008, 1207, 24.

26. EPA Methods, AccuStandard, http://www.accustandard.com/ asi/epa_downloads.php3.

27. E. Psillakis and N. Kalogerakis, J. Chromatogr., A, 2001, 938, 113. 